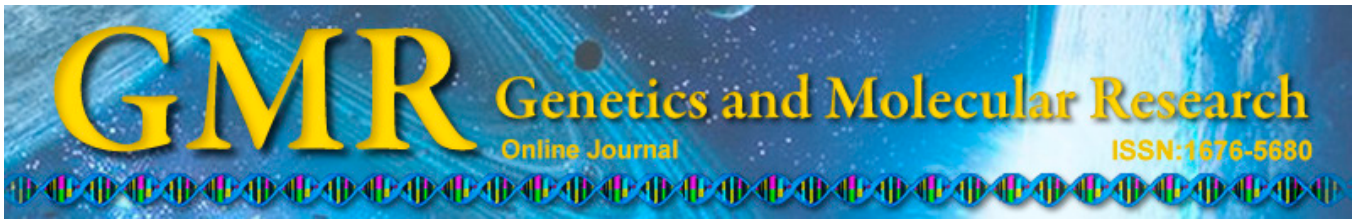

Short Communication

\title{
Sequence variation and gene duplication at the MHC DRB loci of the spotted seal Phoca largha
}

\author{
X.G. Gao ${ }^{1}$, J.B. Han ${ }^{1}$, Z.C. Lu ${ }^{1}$, P.J. Zhang ${ }^{1,2}$ and C.B. He \\ ${ }^{1}$ Liaoning Ocean and Fisheries Science Research Institute, Dalian, China \\ ${ }^{2}$ Marine Mammal and Marine Bioacoustics Laboratory, \\ Sanya Institute of Deep-Sea Science and Engineering, \\ Chinese Academy of Sciences, Sanya, China \\ Corresponding author: C.B. He \\ E-mail: hechongbo@hotmail.com
}

Genet. Mol. Res. 14 (1): 2055-2062 (2015)

Received March 20, 2014

Accepted October 3, 2014

Published March 20, 2015

DOI http://dx.doi.org/10.4238/2015.March.20.15

\begin{abstract}
The major histocompatibility complex (MHC) is one of the most important genetic systems associated with resistance to infectious diseases in vertebrates. The spotted seal (Phoca largha) is one of the most endangered species in China. In this study, we present the first step in the molecular characterization of a DRB-like locus in the spotted seal by analyzing the nucleotide sequence of the polymorphic exon 2 segments, a 288-nucleotide sequence. By examining the segment from a group of 41 individuals, 28 alleles were identified. No deletion, insertion, or exceptional stop codon was detected, suggesting that these alleles could be functional in vivo. The nucleotide and amino acid sequences of the segment both showed a relatively high level of similarity (nucleotides 97\%; amino acids 98\%) to those of Meles meles and Zalophus californianus. The high level of spotted seal MHC-DRB polymorphism revealed in the present study has not been reported for the Phocidae and could be a consequence of the small spotted seal population adapting to the Bohai Sea, which probably has a relatively
\end{abstract}


high level of pathogens.

Key words: Spotted seal (Phoca largha); Sequence variation; MHC; DRB; Gene duplication

\section{INTRODUCTION}

The spotted seal (Phoca largha) is one of the world's endangered mammals, and it is distributed in the Yellow Sea, Sea of Japan and Okhotsk, Bering, Chukchi and Beaufort Seas in the North Pacific Ocean. It is categorized as Critically Endangered Species in China and South Korea because of the destruction of its habitat by human activity. There have been conservation attempts to preserve the animals, such as the Dalian Spotted Seal Reserve of China, which was established in 1992 in the Liaodong Gulf in the Bohai Sea, the most southern of the eight spotted seal sanctuaries across China (Shaughnessy and Fay, 1977; Won and Yoo, 2004).

In the spotted seal population from the Liaodong Gulf, lower genetic variation of $\mathrm{mtD}$ NA sequences was observed in our previous study compared to those from the coast of Hokkaido in Japan and from the Sea of Okhotsk in Russia (Han et al., 2007). This may be indicative of an independent colony of spotted seals in the Liaodong Gulf, which is isolated from the Hokkaido and Okhotsk populations. Information obtained from the spotted seals with satellite-linked tagging in the Liaodong Gulf and Bak-ryoung Island of South Korea has indicated that the spotted seals spend the spring, summer and autumn feeding along the coast of Bak-ryoung Island, but spend the winter breeding in the Liaodong Gulf (Han et al., 2013). The surviving population declined to about one thousand individuals by 2005, even though some protection measures had been taken and seal hunting was prohibited in this region during the past two decades.

The major histocompatibility complex (MHC) is one of the most important genetic systems associated with resistance to infectious diseases in vertebrates. In the vertebrate genome, the MHC genes are among the nuclear genes to have the most polymorphic loci. It has been suggested that species and/or populations with a low level of MHC diversity are particularly vulnerable to infectious diseases because the encoded proteins of the MHC genes play an important role in the immune response against pathogens. MHC variability has been the focus of many genetic studies devoted to endangered species in recent years (Yang et al., 2010; Wu et al., 2012). In general, investigations of MHC have focused on wildlife species that have recently experienced a population decline due to factors such as emerging infectious diseases and negative anthropogenic influences.

In MHC class II genes, the DRB regions exhibit the most elaborate polymorphisms, and these have been extensively characterized in marine mammals, due to their importance in immunological research (Bowen et al., 2004; Osborne et al., 2013). In this study, we examined the loci within the DRB region, with emphasis on the second exon of DRB. This study could provide a platform for the evaluation of the genetic structure and diversity of the spotted seal population in relation to wildlife diseases.

\section{MATERIAL AND METHODS}

A total of 41 specimens were collected from the seals in the Liaodong Gulf between 2005 and 2012. Muscle samples were obtained from 16 dead juvenile seals (under one yearold) accidentally caught in the fishing nets along the coast of Yantai Shandong, Peninsula Jiaodong. Seventeen muscle samples were collected from seals caught by hunters on the coast of 
Dalian, Peninsula Liaodong. All the muscle tissues collected were preserved in $70 \%$ ethanol. After arriving at the laboratory, they were frozen at $-20^{\circ} \mathrm{C}$ until analysis. The remaining eight samples were blood samples collected from the seals in Dalian Sun Asia Ocean World Co., Ltd. DNA from the above tissues was extracted using standard proteinase $\mathrm{K} / \mathrm{phenol} / \mathrm{chloro}$ form extraction (Sambrook and Russell, 2001).

The spotted seal transcriptome has been assembled using Illumina paired-end sequencing and has yielded 354,014 contigs and 178,466 unigenes (Gao et al., 2013). BLAST analysis of all unigenes revealed one sequence with high similarity to the DRB of MHC, and this unigene was selected for further cloning of the DRB of the MHC gene. A pair of specific primers, 5'-GGCGAGTTGAGCCTACAGTGAC-3' (forward) and 5'-CATTCCACGGTGACAGGGCTC-3' (reverse), was designed on the basis of the known sequences reported by Gao et al. (2013) and used to amplify the partial fragment of exon 2 (the DBD region) of the MHC gene. All amplification reactions were carried out using the Applied Biosystems Veriti 96-well thermal cycler (Applied Biosystems, Foster City, CA, USA). The reaction mixture consisted of 20-50 ng genomic DNA, 1X PCR buffer, $1.5 \mathrm{mM} \mathrm{MgCl}, 0.2 \mathrm{mM}$ dNTPs, $200 \mathrm{nM}$ of each primer, and $2 \mathrm{U}$ Ex Taq polymerase (Takara, Dalian, China) in a total volume of $50 \mu \mathrm{L}$. The PCR program was as follows: initial denaturation at $94^{\circ} \mathrm{C}$ for $5 \mathrm{~min}$ followed by 35 cycles of $30 \mathrm{~s}$ at $94^{\circ} \mathrm{C}, 30 \mathrm{~s}$ at $60^{\circ} \mathrm{C}$, and $30 \mathrm{~s}$ at $72^{\circ} \mathrm{C}$, and a final extension step at $72^{\circ} \mathrm{C}$ for $10 \mathrm{~min}$.

The purified PCR products of the 41 individuals were cloned into pMD-18T simple vector (Takara). Eight to ten clones were randomly selected from each individual and sequenced in the forward direction using the M13 forward primer (5'-CATGTGCTACTTCACC AACGG-3'). DNA sequencing was performed by the ABI PRISM 310 Automated Genetic Analyzer (Applied Biosystems) using the BigDye Terminator Cycle Sequencing Ready Reaction kit (Applied Biosystems).

To determine the variable nucleotide sites and unique alleles, the sequences obtained from the DNA sequencing were aligned with ClustalX 1.8, and the alignment corrected by hand. Phylogenetic analysis was performed using the Molecular Evolutionary Genetics Analysis (MEGA) version 3.1 program. A phylogenetic tree, based on currently available spotted seal alleles and allele from Zalophus californianus was reconstructed using the neighbor-joining algorithm (Saitou and Nei, 1987). Bootstrap confidence intervals were obtained from 1000 replicates. Relative frequencies of nonsynonymous substitution were calculated according to the method described by Nei and Gojobori (1986).

\section{RESULTS}

A total of 401 clones from 41 individual seals were sequenced and 288-bp sequences were obtained. In all, 28 distinct sequences (alleles) (Phla-DRB*1-28) were identified (GenBank accession No. KJ546384-KJ546411; Figure 1). Of the 28 unique alleles, 18 alleles were observed in more than one individual, whereas the remaining 10 alleles were only seen in one individual, but were observed in two or more clones. These 10 alleles were further confirmed by a separate PCR and cloning procedure. A total of 94 variable sites were found in these alleles, including 69 transitions and 25 transversions. In addition, 70 nonsynonymous substitutions were also identified, which contributed to the changes of 19 amino acid residues (Figure 2). No insertion/deletion or premature stop codon was detected in these alleles.

The phylogenetic trees based on nucleotide sequences (Figure 3) and inferred amino acid sequences (data not shown) were nearly identical. The sequence similarity between the 
present Phla-DRB alleles and DRB2 genes of Meles meles and Z. californianus varied 96 to 98\% (average 97\%) for nucleotides and 97 to 99\% (average 98\%) for amino acids. When the predicted amino acid sequences were compared with their counterparts in other animals, it was clear that the Phla-DRB alleles did not share the same motif with the DRB2 genes of humans and other mammals (Figure 4).

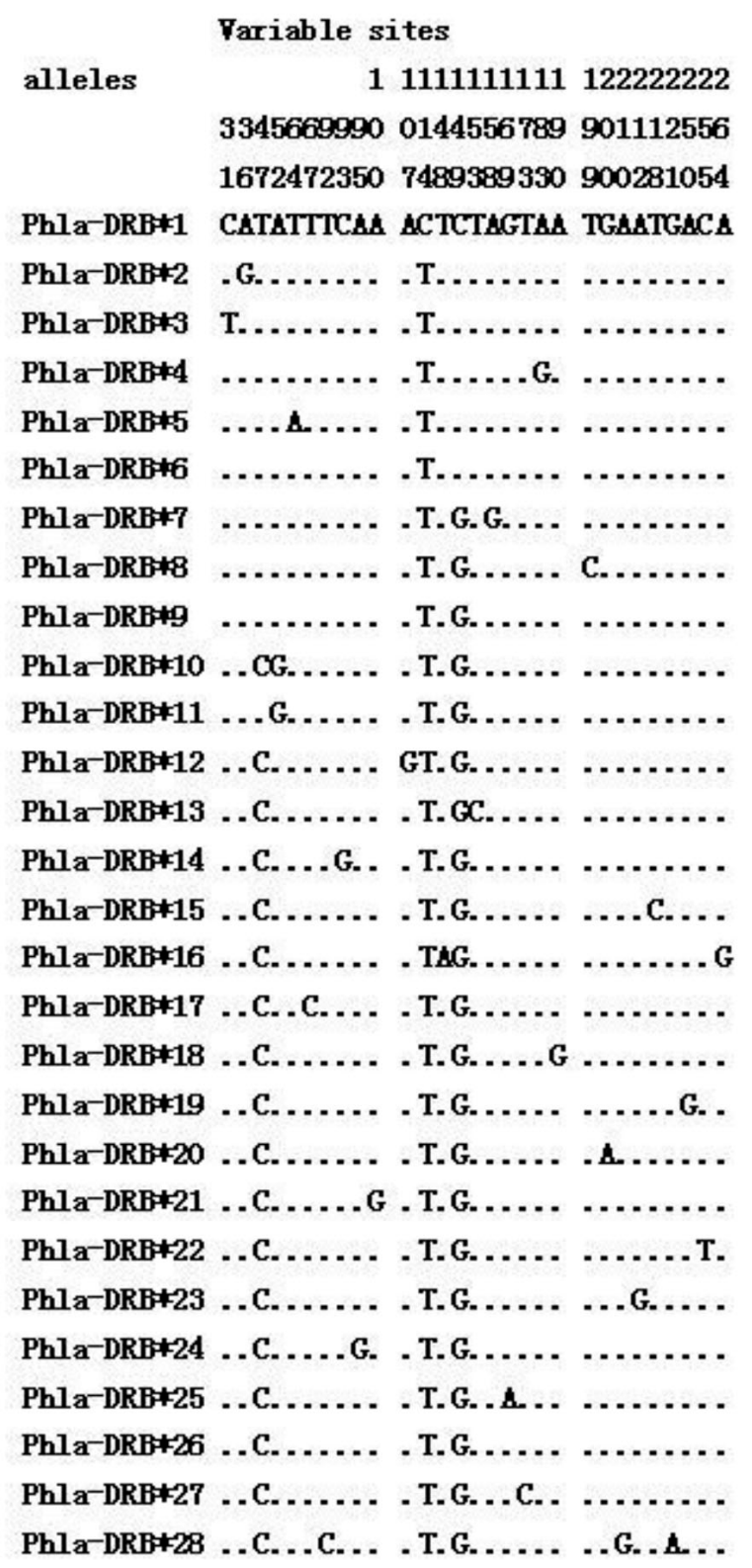

Figure 1. Variable sites of Phla-DRB alleles (Phla refers to Phoca largha). Allele codes are shown on the left. Identical bases are indicated by dots. 
111223394556667888

027121389161360958

Phla-DRB $\$ 26$ PKQLLPHTS RTQHIET

Phlar-DRE\#27

Phla-DRP+15

Phla-DRB+23

Phla-DRE*6

Phla-DRBF7

PhlarDRB†9

Phl a-DRE $\$ 20$

Phla-DRB+4

. A. .....

Phla-DRB*18

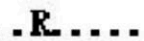

Phla-DRE 288

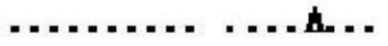

Phla-DRE+19

G. .

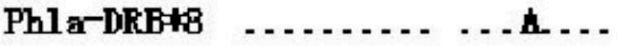

Phla-DRBF5 _...

Phla-DRB

Phla-DRB+9 I. . . . . . . . . . . . .

Phla-DRB+10 ... . . . . . . . . . . . .

Phla-DRB+11 ... . ...... . . . . . .

Phla-DRE\$14 .................

PhlarDRB+1 .......R. . . . . .

Phla-DRB\#17 . . . . P. . . . . . . . . .

Phla-DRB\#21 . . . . . . R. . . . . . . .

Phla-DRBt13 .........P .......

Phla-DRB+22 ................ S.

Phla-DRE $\$ 25$

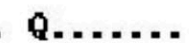

PhlarDRBH24

Phla-DRE $\$ 12$

Phlar-DRB+16

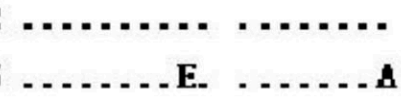

Figure 2. Amino acid sequences of DRB alleles of spotted seal. The numbers above the sequences represent the amino acid positions based on the seal DRB sequences. Identical amino acids in the sequences are indicated by dots. 


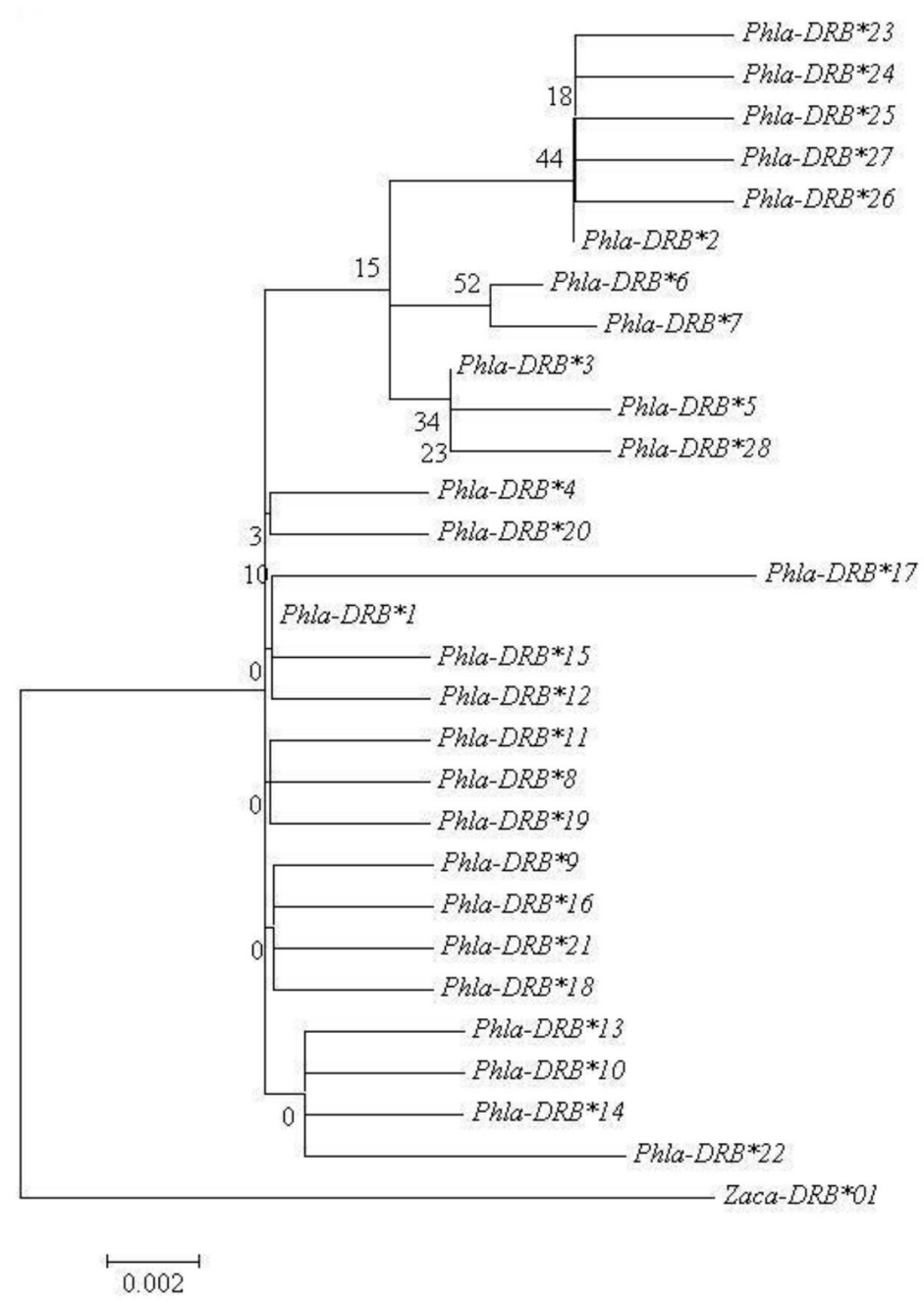

Figure 3. Phylogenetic tree for spotted seal DRB nucleotide sequences reconstructed by neighbor-joining method. Zalophus californianus DRB allele (Zaca-DRB* 01) was used as an outgroup in the analysis. Bootstrap values from 1000 iterations are indicated above the branches.

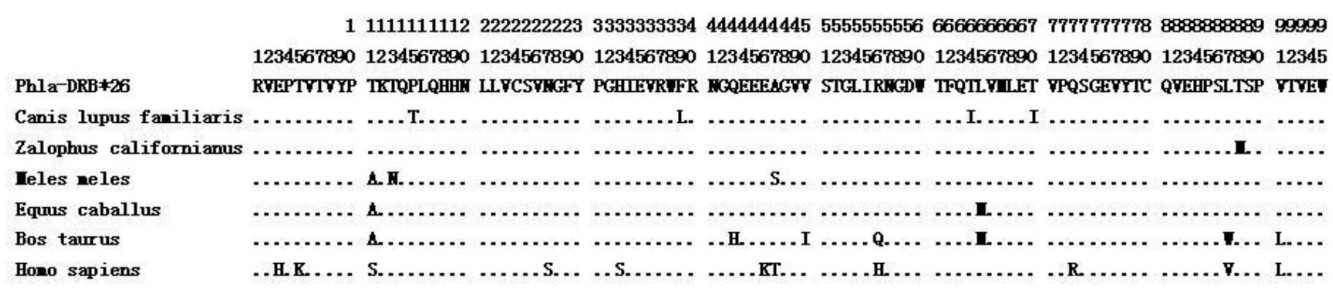

Figure 4. Comparison of DRB amino acid sequences of spotted seal, sea lion, human and some other mammals. 


\section{DISCUSSION}

In the present study, 28 alleles were identified from exon 2 of the MHC-DRB locus from 41 individual spotted seals. The fact that all individuals had more than two alleles suggested that these alleles did not come from the same locus and could thus be regarded as evidence for the existence of gene duplication at the spotted seal DRB locus. Gene duplications have been revealed in many MHC loci in some other animals, for example, the owl monkey (Aotus nancymaae) DRB locus (Nino-Vasquez et al., 2000) and the Baiji (Lipotes vexillifer) DQB locus (Yang et al., 2005). Gene duplication, in combination with allelic sequence diversity would effectively increase the diversity of MHC-encoded proteins and/or protein dimers or polymers, and would thus play an important role in the immune response to various pathogens.

It has been shown that many marine mammals have lower levels of MHC diversity compared to terrestrial mammals (Slade, 1992; Murray et al., 1995). Although several hypotheses have been put forward to explain the reduction of MHC diversity in marine mammals, the simplest explanation is that the low level of MHC diversity is caused by a reduced balancing selection pressure, which in turn is the result of the lower abundance of parasites in marine water as compared to terrestrial environments (Slade, 1992). One problem with this hypothesis is the finding from previous studies that many diseases and epizootics do occur in marine mammal populations (Van Bressem et al., 1998; Acevedo-Whitehouse et al., 2003). Compared to the MHC genes of many other marine mammals, which show low levels of genetic diversity (Slade, 1992; Murray et al., 1995), the spotted seal genome showed evidence of gene duplication and had unexpectedly high levels of allelic diversity and sequence variability. This result was similar to that obtained for Neophocaena phocaenoides asiaeorientalis, whereby more than two unique sequences were identified in one individual (Du et al., 2009). This suggested the possibility of gene duplication at this DRB locus, and indicated that the DRB gene in the Yangtze finless porpoise has potential function and high variability, as well as having undergone strong positive selection.

It is well known that the spotted seal population in the Liaodong Gulf has rapidly declined in the past few decades. Although systematic environmental studies have yet to be conducted, the pollution of the marine environment is expected to become increasingly serious, especially in the Liaodong Gulf. If so, it is likely that the gene duplication and relatively high levels of MHC sequence variability in the spotted seal discovered in this study could be evolutionary adaptations to the marine environment. Furthermore, the high level of genetic variability at the MHC DRB locus was not consistent with neutral mitochondrial and SSR markers (Han et al., 2007, 2010). This inconsistency could be explained by the absence of an association between neutral and fit-related traits in the natural populations (Reed and Frankham, 2001).

\section{ACKNOWLEDGMENTS}

Research supported by the Public Science and Technology Research Funds Projects of Ocean (\#201105011) and the National Natural Science Foundation of China (\#31302178).

\section{REFERENCES}

Acevedo-Whitehouse K, Gulland F, Greig D and Amos W (2003). Inbreeding: Disease susceptibility in California sea 
lions. Nature 422: 35 .

Bowen L, Aldridge BM, Gulland F, Van Bonn W, et al. (2004). Class II multiformity generated by variable MHC- DRB region configurations in the California sea lion (Zalophus californianus). Immunogenetics 6: 12-27.

Du HJ, Zheng JS, Wu M, Zhao QZ, et al. (2009). Isolation and identification of MHC-DRB gene exon 2 in the Yangtze finless porpoise. Acta Hydrobiol. Sin. 33: 804-810.

Gao XG, Han JB, Lu ZC, Li YF, et al. (2013). De novo assembly and characterization of spotted seal Phoca largha transcriptome using Illumina paired-end sequencing. Comp. Biochem. Physiol. Part D 8: 103-110.

Han JB, He CB, Wang XM, Wang Q, et al. (2007). Sequence analysis of mitochondrial tRNAThr, tRNAPro and control region from spotted seals (Phoca largha) in Liaodong Gulf. Fish. Sci. 26: 74-78.

Han JB, Sun FY, Gao XG, He CB, et al. (2010). Assessing the genetic variability of the endangered spotted seal (Phoca largha) in Liaodong Gulf using microsatellite markers. Ann. Zool. Fennici 47: 15-27.

Han JB, Lu ZC, Tian JS, Ma ZQ, et al. (2013). Release studies on spotted seals (Phoca largha) using satellite telemetry tracking technique. Acta Theriol. Sinica 33: 300-307.

Murray BW, Malik S and White BN (1995). Sequence variation at the major histocompatibility complex locus DQB in beluga whales (Delphinapterus leucas). Mol. Biol. Evol. 12: 582-593.

Nei M and Gojobori T (1986). Simple methods for estimating the numbers of synonymous and non-synonymous nucleotide substitutions. Mol. Biol. Evol. 3: 418-426.

Nino-Vasquez JJ, Vogel D, Rodriguez R and Moreno A (2000). Sequence and diversity of DRB genes of Aotus nancymaae, a primate model for human malaria parasites. Immunogenetics 51: 219-230.

Osborne AJ, Zavodna M, Chilvers BL, Robertson BC, et al. (2013). Extensive variation at MHC DRB in the New Zealand sea lion (Phocarctos hookeri) provides evidence for balancing selection. Heredity 111: 44-56.

Reed DH and Frankham R (2001). How closely correlated are molecular and quantitative measures of genetic variation? A meta-analysis. Evolution 55: 1095-1103.

Saitou N and Nei M (1987). The neighbor-joining method: a new method for reconstructing phylogenetic trees. Mol. Biol. Evol. 4: 406-425.

Sambrook J and Russell DW (2001). Molecular Cloning: A Laboratory Manual. 3rd edn. Cold Spring Harbor Laboratory Press, New York.

Shaughnessy PD and Fay RH (1997). A review of the taxonomy and nomenclature of North Pacific harbour seals. J. Zool. 182: 385-419.

Slade RW (1992). Limited MHC polymorphism in the southern elephant seal: implications for MHC evolution and marine mammal population biology. Proc. R. Soc. Lond. B 249: 163-171.

Van Bressem MF, Jepson P and Barrett T (1998). Further insight on the epidemiology of cetacean morbillivirus in the northeastern Atlantic. Mar. Mamm. Sci. 14: 605-613.

Won C and Yoo BH (2004). Abundance, seasonal haul-out patterns and conservation of spotted seals Phoca largha along the coast of Bak-ryoung Island. South Korea Oryx 38:109-112.

Wu HL, Tong CC, Li E and Luo TL (2012). Insight into gene evolution within Cervidae and Bovidae through genetic variation in MHC-DQA in the black muntjac (Muntiacus crinifrons). Genet. Mol. Res. 11: 2888-2898.

Yang G, Yan J, Zhou K and Wei F (2005). Sequence variation and gene duplication at MHC DQB loci of baiji (Lipotes vexillifer), a Chinese river dolphin. J. Hered. 96: 310-317.

Yang WC, Hu JM and Chou LS (2010). Phylogenetic analyses of MHC Class II genes in Bottlenose Dolphins and their terrestrial relatives reveal pathogen-driven directional selection. Zool. Stud. 49: 132-151. 